\title{
arte, invenção, saúde e... bum!
}

art, invention, health and ... bum!

edson passetti; flavia lucchesi

Pontifícia Universidade Católica de São Paulo

\section{RESUMO:}

Vinte anos após a chamada lei antimanicomial, torna-se importante revolver as proveniências da luta antipsiquiatria e a situação atual do controle da loucura como doença mental redimensionada em saúde para se perguntar sobre os efeitos da reforma.

Palavras-chave: antipsiquiatria; saúde pública; arte; invenção; revolução

\section{ABSTRACT:}

Twenty years after the so-called anti-asylum law, it is important to revolve the provenances of antipsychiatry struggle and the current situation of madness control as a mental disease resized as mental health in order to ask about the effects of the reform.

Key-words: antipsychiatry; public health; art; invention; revolution

DOI:10.12957/mnemosine.2021.62177

“onde estão, belos rudes delinquentes, anarquistas, olhos negros, corpos

cálidos dilacerados por cicatrizes? aqueles que você verá serão glutões e bajuladores, e desmaiarão se os vacinar" (fernand deligny).

Talvez esteja na arte a mais explícita constatação de que a cultura perpetuada por uma minoria (aristocracia, elite ou vanguarda) é um efeito da vida organizada por meio de hierarquias, superioridades instaladas, respeitadas, reverenciadas, cultuadas e por vezes, adoradas. E, também, que há uma vida livre como arte continuamente inventada.

Retomar ou prosseguir retilíneo e sem olhar à sua volta para além da expectativa de fronteiras é resultante da arbitrariedade na demarcação da origem do humano, considerada em verso e reverso, em disputas pela definitiva origem verdadeira. Marx e Engels identificam a comunidade primitiva como o espaço da igualdade entre indivíduos e acesso à terra, meta futura projetada e almejada com o histórico alto desenvolvimento das forças produtivas; Proudhon, ao contrário, situa a origem humana no mesmo ponto da criação divina: a comunidade é a base do regime fundado na autoridade superior, produz a aparição do patriarca e a correção da injustiça, decorrente da exploração do fraco 
pelo forte devido às intempéries da natureza, resultando na aparição da propriedade. Se, para Marx e Engels, há uma evolução que nos levaria ao socialismo e ao comunismo, dimensionados por Lenin, para Proudhon a luta contra a autoridade centralizada, a interceptação do retorno da comunidade e qualquer forma de propriedade seria equacionada pela luta constante das forças, tanto contra a Ideia de Kant quanto ao Espírito de Hegel. O grande embate durante os séculos XIX e XX entre anarquistas e comunistas, sempre deixou claro que eles não buscaram complementar-se. Se a dialética marxista exige a síntese, a dialética serial proudhoniana (e é sempre bom lembrar que Proudhon não conhecia Hegel quando conheceu Marx) a evita por reconhecer que autoridade e liberdade formam um duplo indissociável e que a vida livre depende de relações que tendem à série liberdade. Se os comunistas se veem como condutores de consciência, incluindo-se como guias para anarquistas, estxs, ainda na arbitrária demarcação da infância da humanidade, não admitem condutores, hierarquias, determinações ou qualquer bafejo de pastorado. Na arte da revolução, são duas forças que conduzem (comunistas) ou somam (anarquistas) contra as desigualdades e o capitalismo. Na arte da invenção são forças distintas, uma previsível e mimética (os comunistas) e outra que se revolta e inventa (xs anarquistas).

Arte livre é arte apartada de hierarquias consolidadas. Para Marx, no futuro o indivíduo e a arte se fundirão, pacificados no comunismo. Para Proudhon, no presente, pelo mutualismo e o federalismo, a arte é intensa, repleta de tensões como bem assinalou Gustavo Simões a respeito da publicação em português de Do princípio da arte e de sua destinação social, enfatizando como Proudhon situou a arte convencional vinculada à religião até a aparição de Courbet (SIMÕES, 2013). Proudhon morreu um ano antes de Courbet, realizar, em 1866, “A origem do mundo", óleo sobre tela que chegou a ser alvo recente de censura na Internet, e da pintura póstuma de seu retrato em 1865. Courbet já era reconhecido, entre outras obras, pelo perturbador "Auto-retrato" de 1843. Foi explícito sobre a arte e a estética em sua Carta aos artistas de Paris de 18 de março de 1871, em plena Comuna de Paris: “as administrações anteriores que governaram a França quase destruíram a arte ao protegê-la e ao suprimir sua espontaneidade" (COURBET, 2009: 123). Ele estava sintonizado com o perigo da arte se tornar refém de mecenas, de editais de Estado, ideias de curadores, até mesmo após o fim do domínio da estética aristotélica com a instauração da arte moderna. Max Stirner (2003), a respeito da arte, encontra-se próximo a Proudhon e a Courbet, traçando a íntima relação entre religião e arte. Foucault, no final do século XX e de sua obra, não só, mas também, pelo percurso 
cínico em seu derradeiro curso, explicita a continuidade das lutas pela contenção das hierarquias e da autoridade centralizadora e importa-se com a estética da existência, já indicada desde o final de História da loucura na idade clássica: a vida como obra de arte, a vida intensa e militantista (FOUCAULT, 2011).

Não é simples fazer da vida uma obra de arte, resistir e inventar. Depois da Comuna de Paris, muitos revolucionários sobreviventes que não foram mortos, presos e deportados, acabaram confinados em hospícios. Mais tarde isso seria saudado pelo fundador da Antropologia Criminal, Cesare Lombroso, quando da publicação de seu livro Os anarquistas em 1894, mas já presente na construção da periculosidade desde 1876, com $O$ homem delinquente. Ao mesmo tempo, o militantismo foi minguando em função da militância institucional em sindicatos e partidos. A arte moderna, enfim, encontrou a sua derrocada no realismo socialista stalinista e depois desta tirania, com Krushev veio a revisão dos gulags, deslocando os prisioneiros políticos do campo de concentração e de trabalhos forçados para a condição de doentes mentais destinados aos hospícios.

A vida como obra de arte é uma consistente tradução da vida livre na utopia acomodada dos revolucionários marxistas; na heterotopia das existências anarquistas no presente; na inquietação constante contra a subserviência nas relações como situou Stirner, um anarquista nos anarquismos, não lhes dando sossego; nos questionamentos de Foucault sobre a origem dos homens e atiçando revoltadxs. A vida como obra de arte é mais que utopia, ela é presencial sem coincidência temporal ou determinações históricas. É invenção da vida, de um militantismo outro que se situa e combate a anti autoridade centralizada, absoluta, universal.

A vida de certos grupos chamados primitivos desviou-se das situações proporcionadoras para que houvesse a autoridade centralizada no Estado (CLASTRES, 1974). Nas culturas indígenas que ainda permanecem "isoladas" e que rejeitam, mesmo desconhecendo, as benesses da política, das leis e da saúde pública, há uma relação com a autoridade que se indispõe à centralização governamental. Ali permanece, o que por nós é desconhecida e que perseguimos como existência livre, que se dispensa, também, de um equacionamento ou não a partir de uma origem arbitrária. Esta arte de existência está estampada no corpo, projetada nos objetos de uso e alimentação, em vestimentas, habitações, mas principalmente em relações com crianças, bichos e plantas, o ambiente, algo do dia e da noite que não coloca a necessidade de se construir uma religião ou qualquer instância superior à da vida das pessoas. A relação possível com o sobrenatural é sem transcendências. Uma forma de organização, enfim, que não toca nas proximidades 
morais da cultura de herança europeia, para nos restringirmos ao que se convencionou definir como Ocidente.

A arte rupestre, a arte indígena muito estudada pela antropologia, a arte moderna rompendo cânones da estética aristotélica, ou mesmo a arte realista da Comuna de Paris, abandonando os donos dos artistas para explicitar que somos todos artistas de uma obra exterior ou de si: há a arte da existência que atravessa a história e os mais estranhos espaços pela produção de invenções feitas por pessoas e que não suportam ser calibradas por um conceito; é sempre uma experimentação.

Há, também, as obras de arte criadas pelos rompimentos que reiteram um novo, um alternativo, uma renovação ao mesmo tempo em que o domínio de uma outra minoria sobre equipamentos, técnicas e composições consolida o regime de alternâncias estéticas. Tudo isso é a arte estudada pela estética, pela filosofia, as ciências humanas, a crítica, os livros escritos por conhecedores abalizados, museólogos, curadores. Esta arte está nas mãos e domínio de alguns, como acesso, produção, compra, coleção e definição do que é arte em ambientes públicos e privados; esta arte que se diferencia de artesanato, cultura popular, de massa...; enfim, modos pelos quais os saberes hierarquizadores leem a continuidade da arte como produção de uma minoria para a apreciação, aquisição, até instalação em museus, galerias, territórios ao ar livre ou lares de uma minoria para outras minorias ou destinadas ao jargão "público em geral". Elas se espelham, se atraem e perpetuam relações.

Até mesmo a loucura e a chamada doença mental tiveram papéis importantes na identificação do objeto de arte desde o Renascimento, passando pelos bufões no teatro, a aceitação do riso na Idade Média... Deixando-se de lado tanto as experimentações pós IIGuerra Mundial de Dubufett, com a arte bruta na Suíça (PASSETTI, 2009), quanto de Nise da Silveira, no Brasil, no Museu do Inconsciente em Engenho de Dentro-RJ (Leon Hirshman ${ }^{1}$, o documentário Nise ${ }^{2}$; MAGALDI, 2020) e até mesmo figuras emblemáticas como Antonin Artaud no século passado, aos propósitos deste ensaio, está em questão desvencilharmo-nos da arte de minorias para minorias, também como mixed de loucura e saúde mental, excentricidades, padrões estéticos e avaliações críticas na produção de objetos de arte (pinturas, esculturas, instalações, música, canto, teatro, cinema e literatura) que atestam o reconhecimento da arte como bem superior capaz de mexer com subjetividades, alterar mercados e concepções estéticas, e mesmo quando abalam a centralidade da autoridade de saber e a sinfonia de verdades, acabam se acomodando aos 
padrões estéticos culturais vigentes. Importa-nos a arte como demolição, revolta, invenção de vida outra. Arte a surpreender.

Tanto a arte pela loucura como a arte dos grupos tribais inventam e provocam a ruínas dos cânones, seja porque são produzidas por pessoas que se relacionam fora das convenções educacionais, culturais e de convivência e conveniência, seja por outras culturas, seja por não se importarem, negarem ou desconhecerem o juízo de valor ocidental que domina por meio de minorias. Claro que houve e haverá exceções, sejam elas do porte de artistas no século XIX identificadxs com os anarquismos, anticonvencionais na conduta sociocultural e na forma de se afastarem da obtenção de reconhecimento de mercado ou estético, com arrojados estilos de vida, escritas transformadoras, expositores da situação real e imaginária dos humanos, muitas vezes levadxs ao suicídio, às prisões e hospícios por regimes políticos declaradamente autoritários ou camuflados de realizadores dos interesses coletivos. A loucura, a cultura tribal contra o aparecimento do Estado e xs antipolíticos anarquistas não aspiram ocupar um lugar, mas inventam lugares, são heterotópicxs em percurso (PASSETTI, 2002).

Este artigo trata os feitos de saúde mental governamental, promovendo a mutação da luta antipsiquiátrica em antimanicomial, um tanto de uma história da liberdade da loucura, das condições favoráveis de parcerias em revoluções do século passado e na formalização jurídica do controle a céu aberto da loucura como saúde mental. É preciso arte e ser arteirx.

\section{invenção}

"rejeite os que vêm se oferecer: não vá procurar os que se afastam de você, e conte os que ficam. se só tiver um, comece com esse" (fernand deligny).

Nietzsche deixara escancarado que a criação era algo voltado ao transcendental. Foucault (2005) retomou o percurso genealógico para situar nas conferências do Rio de Janeiro, em 1973, publicadas como A verdade e as formas jurídicas, que:

meu objetivo será mostrar-lhes como as práticas sociais podem chegar a engendrar domínios de saber que não somente fazem aparecer novos objetos, novos conceitos, novas técnicas, mas também fazem nascer formas totalmente novas de sujeitos e de sujeitos de conhecimento. O próprio sujeito de conhecimento tem uma história, a relação do sujeito com o objeto, ou, mais claramente, a própria verdade tem uma história. Assim, gostaria particularmente de mostrar como se pôde formar, no século $X I X$, um certo saber do homem, da individualidade, do indivíduo normal ou anormal, dentro ou fora da regra, saber este que, na verdade, nasceu das práticas sociais, das práticas sociais do controle e da vigilância. E como, de certa maneira, esse saber não 
se impôs a um sujeito de conhecimento, não se propôs a ele, nem se imprimiu nele, mas fez nascer um tipo absolutamente novo de sujeito de conhecimento. Podemos dizer que a história dos domínios do saber em relação com as práticas sociais, excluída a preeminência de um sujeito de conhecimento dado definitivamente, é um dos primeiros eixos de pesquisa que agora lhes proponho (FOUCAULT, 2005: 8).

O filósofo-historiador-jornalista...em suas diversas epidermes inquietas sobre acontecimentos, já era muito conhecido naquele ano desde o seu inesperado sucesso de vendas com As palavras e as coisas. Porém, o que mais sobressaía em Foucault e suas pesquisas era uma deliberada invenção que abalava os estabelecidos patamares dos saberes. Anos mais tarde, em 1980, George Canguilhem, que ao seu modo fora orientador do doutorado de Foucault, em conferência na Sorbonne, introduz-se em um tema fortemente nietzscheano ao dizer que "inventar é criar informações. Perturbar hábitos de pensamento, o estado estacionário de um saber" (CANGUILHEM, 2006: 196). Inventar é uma arte.

Destemidos intelectuais no pós-II Guerra Mundial promoveram uma reviravolta na instável situação da psiquiatria desde o fim do governo do nacional-socialismo alemão. Sabe-se que, às voltas com a administração de anormais na sociedade, para o nazismo o que era internação transformou-se, rapidamente, em local de extermínio de loucos (tidos como doentes mentais), deficientes, acamados crônicos, antes mesmo da investida contra judeus e o projeto de solução final. A psiquiatria, assim como a antropologia criminal e a criminologia contribuíram de modo decisivo, na democracia e antes mesmo dos fascismos, para os confinamentos dos prisioneiros, por vezes em espera até a execução da pena de morte, dos loucos em manicômios para extermínio ou desterro perpétuo, de infratores acusados de crimes acompanhados de condutas anormais em manicômios judiciários, sem falarmos da gradativa edificação de prisões para crianças e jovens. Tudo blindado com as devidas legislações e revestidos de expectativas de ressocializações e normalizações. Etiquetados com medida de proteção da sociedade, às pessoas e aos próprios ensandecidos ou os chamados criminosos encarcerados. Alguns intelectuais do pós II-Guerra Mundial, introduziram a urgência de uma luta antipsiquiatria que atingiria, simultaneamente, situações autoritárias e democráticas no capitalismo, assim como o socialismo autoritário da URSS à China, para além das denúncias de dissidentes ou propagandas ideológicas abundantes depois de instalada a chamada Guerra Fria.

Invenção de algo perturbador. Deslocamento de perspectiva, ou melhor, invenção de uma perspectiva outra, que rompia com os enclausuramentos disciplinares, o saber produzido na instituição austera como a psiquiatria, e atingia, em cheio, os hospícios. No 
passado recente as escolas anarquistas também tinham implodido as disciplinas, em muito apoiadas no método do barcelonês Ferrer y Guardía, que não era anarquista. Foucault situava, desde o reconhecimento internacional de seu doutorado, e a partir de sua larga experiência com os saberes da psicologia, também como professor, que sua analítica genealógica passava a ser pertinente, mais do que nunca, depois da guerra. Foi mais uma de suas passagens intensas pelo Brasil nestes primeiros anos de 1970, como esmiuçou Heliana Conde (2016). Na sua bagagem de conferências trouxe "coisas possivelmente inexatas, falsas, errôneas, que apresentarei a título de hipótese de trabalho; hipótese de trabalho para um trabalho futuro" (FOUCAULT, 2006: 7) ${ }^{3}$.

O papel do intelectual é o de não só mostrar os efeitos repressivos:

a escola não é só uma maneira de ensinar e ler, escrever e comunicar o saber, mas também um modo de impor. O mesmo acontece em relação à psiquiatria, que foi o primeiro dos domínios nos quais tentamos diagnosticar esta imposição. O aparelho psiquiátrico não foi feito para curar, mas para exercer um poder determinado sobre uma certa categoria de indivíduos (FOUCAULT, 2011b: 311).

O intelectual deve ir além para "mostrar que o poder é ainda mais pérfido do que isso: ele não consiste apenas em reprimir — impedir, opor obstáculos, punir —, mas penetra ainda mais profundamente do que isso ao criar o desejo, ao provocar o prazer, produzindo saber" (FOUCAULT, 2011b: 311).

Foucault viu-se próximo de David Cooper e Ronald Laing, fortemente marcados pelo existencialismo de Jean-Paul Sartre, apesar de declarar desconhecê-los durante a redação do seu História da loucura na idade clássica, e menos próximo do liberal Thomas Szasz. Cooper era o mais radical, pretendendo abalar para abolir o saber psiquiátrico do domínio das pessoas, e com quem Foucault participou de mesa sobre a liberação de Vladimir E. Borissov do hospital psiquiátrico especial de Leningrado, em outubro de 19774 Laing pretendia não assumir a rubrica antipsiquiatria e encontrar a verdadeira psiquiatria, a medicina da alma; Szasz não se via nem psiquiatra nem na antipsiquiatria, designação da qual se afastou por considerar que os antipsiquiatras, mediante outras justificativas, utilizavam técnicas coercitivas. Ainda nos anos 1960, Franco Basaglia iniciou, na Itália, com o apoio dos habitantes de Trieste, a desativação manicomial, efetivada em 1978.

Entre os anos 1950 e 1960 o domínio da psiquiatria se viu abalado, mesmo que somente a partir de análises críticas a respeito do poder repressivo intrínseco ao seu exercício. Foucault constata que as críticas giraram em torno das instituições, mas que "depois das mudanças operada em 1968, foi preciso abordá-lo em um outro registro" 
(FOUCAULT, 2011b: 312). Afinal, “os grandes movimentos, por volta de 1968, direcionavam-se contra esse tipo de poder [implícito, invisível, ligado às instituições de saber, de saúde]" (FOUCAULT, 2011c). Esta constatação reitera o que mostrara dois anos antes, em 1973, sobre o poder médico de decidir sobre o paciente anormal em seu estado mental. Foucault pensava em tratamento longe dos divãs e no local onde se vivia (similar a Basaglia). Havia algo, segundo ele, que vinha da Revolução Espanhola sobre como lidar com pessoas tidas como loucas.

Entretanto, o que era movimento antipsiquiatria aos poucos foi se tornando antimanicomial, mais próximo de Laing, talvez de Szasz, e híbrido em relação a Cooper e Basaglia. Todavia, o que de melhor ficou, deste movimento dos anos pós II-Guerra Mundial e precisamente do acontecimento 68 é que práticas anti, como a antipsiquiatria, colocavam em xeque a continuidade das instituições centralizadoras e terminais de saber e poder de exclusão como os manicômios e as prisões. Se Foucault estava correto ao indicar que se consideramos efetivamente que "o sistema penal em seu funcionamento atual é inadmissível, será preciso admitir que ele faz parte de um sistema de poder que compreende a escola, os hospitais, etc. E todos estes poderes são postos em questão" (FOUCAULT, 2011b: 319). Uma luta antipsiquiátrica pode se acomodar em soluções antimanicomiais, e isto não quer dizer, obrigatoriamente, fim dos hospícios ou dos procedimentos de mortificação e desprezo próprios das instituições austeras. Pode ser apenas mais uma reforma de saber e poder, de construção de uma verdade.

A invenção não vem de dentro, está relacionada ao fora e ao querer enfrentar o que está em condições propícias para morrer (STIRNER, 2009), por meio de relações que se estabelecem entre xs que se apartam da hierarquia centralizadora, dos absolutos, do universal, do transcendental. Está em questão o anti, por ser antirreligioso, antijurídico, antipolítico, antissoberania; por interceptar e dissolver o discurso do sujeito sobre si mesmo, sob a forma de confissão; é o fim do requisito psiquiátrico, exigindo que o paciente se reconheça como louco para estar habilitado ao tratamento confinado. Tudo em nome da reforma, da mortificação da pessoa em função do ajustamento de conduta; da aceitação do anormal degenerado em possível recuperado; da obtenção da confissão pela tortura, o acordo tácito entre a justiça e polícia: aceitar, reformar, mudar para fortalecer a instituição.

A confissão, a direção de consciência, a pedagogia, a psiquiatria do século XIX são técnicas que precederam a psicanálise como continuidade e não como ruptura. Psiquiatria, psicanálise, psicologia, o campo psi é o que mais se fortalece pelo 
confinamento, pela sua privatização liberal voltada aos ajustes diante de adversidades; pelo controle monitorado a céu aberto na atualidade. Em certo sentido, o campo psi é fortemente decisivo para a recomendada conduta resiliente no presente, quando os anormais deixaram de ser doentes mentais e passaram a ter seus transtornos tratados com medicalização psiquiátrica ampliada e combinada a outros saberes médicos, como os do pediatra no tratamento de crianças e de jovens com condutas precocemente constatadas como degradadas, e intervindo para como preveni-las.

A passagem da luta antipsiquiátrica para a antimanicomial, de um lado, é resultante do enfrentamento direto às relações saber-poder psiquiátrico e de supressão do confinamento disciplinar de exclusão, em nome de uma suposta futura reintegração ou ressocialização; de outro lado, é resultante da acomodação crítica que escolhe um novo espaço em meio aberto ou semi-aberto (porque regulado para não ser contínuo, considerando-se o direito do louco) para as práticas antimanicomiais que combinarão relações pautadas em horizontalidades e centralidades, ou mais uma "grande" reforma. Porém, os limites da crítica, situam a continuidade do confinamento ao louco, doente mental, drogadito ou transtornado que comete uma infração e está destinado ao confinamento compulsório ou involuntário quando incomoda e supostamente ameaça cometer uma infração, atentar contra o outro, a sociedade ou a si mesmo. Mesmo que se diga que a luta antimanicomial levou adiante o direito do cidadão livre para a internação voluntária e obstrução das práticas involuntárias (Lei 10.216 de 6 de abril de 2001) ${ }^{5}$, pouco ou nada se faz mediante as internações ainda hoje, em hospícios e em comunidades terapêuticas religiosas (predominantemente evangélicas), por se tratar de uma questão moral. E a moral antecede a lei.

A antipsiquiatria se tornou formalmente, pela lei em antimanicomial e produção de variedade de empregos, ocupações, controles, relatórios, análises e medicações voltadas para a chamada redução do sofrimento, enquanto saber e poder. Supuseram dar realidade à alegada utopia da antipsiquiatria e acabar com esse papo todo (e tolo) de invenção. $\mathrm{O}$ discurso antimanicomial passou a ser a nova cara dos reformadores fortalecidos.

\section{saúde}

"construir uma fortaleza. trabalho de escravo ou jogo maravilhoso. tudo está na forma de fazer" (fernand deligny). 
$\mathrm{Na}$ Revolução Espanhola, anarquistas experimentaram também outras maneiras de lidar com as pessoas consideradas loucas. Em meados de julho de 1936, médicos que integravam a CNT (Confederación Nacional del Trabajo) e a Organización Sanitaria Obrera, associaram-se no que foi nomeado como Control Sanitario Confederal para enfrentar os problemas de saúde que aumentaram com as batalhas constantes contra os fascistas. Quando a CNT-FAI (Federación Anarquista Ibérica) aderiu ao governo da Generalitat, o anarquista Félix Martí-Ibáñez aceitou o cargo de diretor geral de Sanidad y Asistencia Social, em $1^{\text {o }}$ de outubro de 1936 e, juntamente com outros médicos e trabalhadores, instigou práticas autogestionárias no Control Sanitario Confederal.

Cerca de um ano antes, o jovem Martí-Ibáñez fundou uma clínica popular em Barcelona, onde atuava como médico-psicólogo, voltado à psicossexologia. Escrevia com frequência em jornais e revistas anarquistas, especialmente expondo suas reflexões sobre sexualidade e a defesa de uma educação sexual — atravessado por certo pensamento eugenista, cientificista e higienista, incorporando as noções de doença e normalidade, porém em ruptura com a moral religiosa que se imiscuía entre muitxs anarquistas. MartíIbáñez foi um dos primeiros a confrontar a moral judaico-cristã que condenava a chamada homossexualidade e a defender o aborto, medida que implementou por decreto em dezembro de 1936. Segundo Cleminson (2008), Martí-Ibáñez era devoto à ciência e sua defesa do aborto e da chamada homossexualidade não era pela liberação, mas por anseios evolucionistas, muito atrelados à eugenia. Ele diferenciava "homossexualismo-inversão" de "homossexualismo-perversão", estabelecendo novas normalidades quanto à sexualidade.

O programa da Generalitat instituiu serviços de saúde descentralizados, divididos em comarcas, que incluíam dispensários psiquiátricos. Esta divisão possibilitava considerar questões específicas geográficas, culturais, sociais e econômicas de cada localidade. Buscavam levar até as montanhas mais remotas da Catalunha as "inovações da medicina moderna" (MARTÍ-IBAÑEZ, 1937: 34, apud CORNELLIS, 2010: 11). Permitiam aos pacientes acometidos por "doenças mentais" que continuassem a viver onde estavam, próximos de suas famílias e amigos, que também se envolviam nos cuidados, acompanhados dos revolucionários e orientados pelas equipes médicas; “em um regime aberto e fraternal em vez do interior dos estabelecimentos [de internação]" (MARTÍ-IBÁÑEZ apud LLAVONA; BANDRÉS, 1998: 672). 
No âmbito do governo da Generalitat, segundo Martí-Ibáñez, realizaram uma reviravolta na psiquiatria.

Devido aos obstáculos que o capitalismo sempre colocou a todo tipo de reformas, havia na Catalunha manicômios (...) o que não existia eram serviços psiquiátricos bem organizados (...). E era urgente reorganizar a luta contra as doenças mentais, porque a guerra e a Revolução sempre foram grandes períodos de agitação coletiva, nos quais choques físicos e morais, privações, etc., revelavam muitos transtornos mentais latentes. (...) As novas autoridades se apoderaram gradativamente de todos os hospitais psiquiátricos e, não se contentando em resolver o internamento dos enfermos catalães $e$ de um grande número de refugiados, propuseram uma reforma do atendimento, [onde] foram montados novos quartos e enfermarias (...), usando da laborterapia como recurso curativo, assim como o aspecto esportivo e cultural foi cultivado por meio da criação de campos de jogos, bibliotecas e pinturas cênicas (MARTÍ-IBÁÑEZ apud LLAVONA; BANDRÉS, 1998: 671-672).

Os diagnosticados como "psiconeuróticos" podiam viver em uma fazenda na comarca catalã da Horta. Entendia-se que estes pacientes não precisavam de asilo, mas de "um local de descanso, trabalho e isolamento, onde podiam ser estudados psicologicamente e tratados de acordo com as normas psicoterapêuticas indicadas" (MARTÍ-IBÁÑEZ apud LLAVONA; BANDRÉS, 1998: 671-672).

No intuito de acessar as técnicas e "inovações da medicina moderna”, MartíIbáñez convocou, em novembro de 1936, a Conferencia de Asistencia Psiquiátrica e Higiene Mental. Nesta ocasião, apresentou seu programa para a formação de equipes médicas e, especialmente, de enfermeiros. Após 10 meses participando do governo, Martí-Ibáñez se demitiu em 22 de fevereiro de 1937. Em agosto se empregou como médico na MZA (Compañía de Ferrocarriles de Madrid a Zaragoza y Alicante) e depois serviu nesta função ao Ejército del Este. Com a derrota republicana, em fevereiro de 1939, ele fugiu, atravessou os Pirineus e adentrou na França, onde esteve somente de passagem. Embarcou para os Estados Unidos para fazer uma carreira de sucesso na medicina, na academia e na indústria farmacêutica.

O seu trajeto de fuga foi semelhante ao de outros médicos que tomaram parte na Revolução Espanhola como Francesc Tosquelles e Salvador Vives Casajuana.

Tosquelles foi médico-chefe dos serviços psiquiátricos na frente sul da Catalunha. Em Almodóvar del Campo, ele montou uma Comunidade Terapêutica, na qual recrutava pessoas sem formação específica, como pintores, escritores, padres e putas, para serem agentes de saúde. Evitava os profissionais, inclusive psiquiatras, pois considerava que eles carregavam hábitos e ideias fixas do exercício da profissão e preconceitos em relação à loucura. Experimentou práticas terapêuticas voltadas também aos médicos e 
enfermeiros que estavam em meio às batalhas e seus efeitos, por vezes, enlouquecedores. A mudança de perspectiva que a revolução e a guerra traziam, muitas vezes, abalava as crenças na autoridade médica e científica e empurrava para romperem com o modo de vida burguês 6 .

Foucault indicara em conversa com o Jornal da Tarde, em São Paulo, no ano de 1975, que "na França, a interrogação sobre o hospital, o hospício e a prática psiquiátrica é antiga. De todo modo, na época da guerra, em um hospital chamado Saint-Alban, médicos espanhóis que durante a guerra civil haviam feito experiências antipsiquiátricas e foram obrigados a se refugiar na França, começaram estas pesquisas (FOUCAULT, 2011c: 351). Conde (1998; 2020), também interessada no assunto, havia focado a presença do médico Francesc Tosquelles (depois, François Tosquelles) ao encontrar a mesma procedência libertária. Entretanto, Alonso (2014) traz uma ampliação a mais na relação libertarismo-antipsiquiatria, apresentando ao lado de Tosquelles outro médico importante e que se manteve distante dos fundadores da antipsiquiatria. Trata-se de Max Hodann:

o Hodann era judeu e Tosquelles, educado e criado em um ambiente catalão, sempre se sentiu membro de uma comunidade 'ocupada'. Os dois viveram suas adolescências e juventudes na confluência de suas formações universitárias e a decomposição do regime institucional, político e social: Hodann, a Primeira Guerra Mundial e a queda do Império alemão, e Tosquelles a ditadura de Primo de Rivera e a queda da monarquia de Alfonso XIII. Desde jovens ambos participaram de movimentos políticos da esquerda revolucionária, comprometendo diretamente sua prática profissional como médicos com seus ideais políticos revolucionários e superando o velho elitismo dos partidos sociais-democratas. Do ponto de vista teórico, Hodann y Tosquelles são 'enquadráveis' na confluência do pensamento de Marx e Freud" (ALONSO, 2012: 63).

A experiência de Tosquelles, como vimos, aconteceu em La Mancha, no Hospital de Almódovar del Campo; a de Hodann em La cueva de la Potita, também em La Mancha, e ambas foram pioneiras em "comunidade terapêutica", mais ou menos sintonizadas com a do Sanatório Psicoanalítico de Tegel, dirigido por Ernst Simmel, nas proximidades de Berlim, de 1927 a 1931. "Entre 1937 e 1939 (...) levaram adiante duas experiências renovadoras quanto à assistência psiquiátrica e psicoterapêutica (...), adiantando-se em várias décadas à futura psiquiatria comunitária, à psiquiatria de setor, à psicoterapia institucional e inclusive à antipsiquiatria (ALONSO, 2012:48).

Tosquelles e Hodann foram jovens próximos do que o marxismo poderia oferecer de mais libertário junto com os anarcossindicalistas da CGT. Coisas de revoluções como já ocorrera na Comuna de Paris, em 1871, e na Revolução Russa dos dois primeiros anos. O possível entre estilos de vida diferentes, mas passíveis de convivência em períodos 
revolucionários contra desigualdades estruturais. Depois, quando a revolução se institucionaliza, o que era parceria rapidamente se desfaz entre adversários e imediatamente em inimigos. Talvez este tenha sido o grande quisto das revoluções inspiradas na francesa de 1789, nos séculos XIX e XX.

Toquelles e Hodann estavam apartados do stalinismo e dos reformismos. Hodann, permeado pela radicalidade do grupo espartaquista de Rosa Luxemburgo, Franz Mehring e Karl Liebknecht na Social-Democracia Alemã, e Wilhelm Reich. Com Magnus Hirschfeld esteve envolvido no Instituto para o Estudo da Sexualidade e na Liga Internacional para Reforma Sexual, onde defendiam a chamada homossexualidade e a masturbação. Seu posicionamento nesta luta foi insuportável para o Partido, que o acusou de "conspirador anarquista". As elaborações de Hirschfeld e de Hodann reverberaram entre anarquistas pelo planeta e, na Espanha, em Martí-Ibáñez e A. G. Llauradó, que na mesma época incomodou também muitxs libertárixs com seus escritos no periódico Estudios em defesa do sensualismo e da masturbação (CLEMINSON, 2008). Tosquelles estava tocado pelo marxismo, via Trotsky e o POUM (Partido Obrero de Unificación Marxista), que ajudou a fundar, e Freud. Para Tosquelles e Hodann, como para MartíIbánez, a Revolução Espanhola abriu possibilidades para que leituras, breves experiências e a vida intensa em busca de firmar as práticas de liberdade pudessem ocorrer naquelas condições entre médicos, equipes e as pessoas dos lugarejos, por homens afastados dos protagonismos tão em voga hoje em dia, para colocarem setas nos percursos que deram mais tarde em antipsiquiatria e comunidade terapêutica.

Em março de 1939, Tosquelles, com a família, fugiu para a França e foi parar em um campo de concentração em Sept-fonds. Lá iniciou um trabalho como psiquiatra, contando com o auxílio de uma enfermeira especializada, "um pintor e um violinista que nada sabiam de psiquiatria, mas que conheciam arte" (TOSQUELLES apud GOMEZ, 2010: s/p). Tosquelles destacava que o mais importante dessa experiência, neste lugar de horror que à primeira vista se assemelhava a um hospital psiquiátrico, foi poder abrir a porta para a saída de algumas pessoas. No ano seguinte, foi indicado pelo companheiro de Revolução, Salvador Vives Casajuana, para trabalhar no hospital psiquiátrico de SaintAlban. Casajuana, durante sua permanência na Revolução Espanhola e sobre quem há poucos registros hoje, foi superintendente do ministério dirigido por Martí-Ibáñez, responsável por questões relativas à “doença mental”.

Quando chegou em Saint-Alban, Tosquelles encontrou um hospital insalubre e lotado, com cerca de 600 a 700 internos. Lá ocupou os aposentos onde ficara Antonin 
Artaud (CONDE, 1998). Em meio à Guerra, o hospital tinha se tornado um local aberto, servindo de passagem para camponeses e para circulação de mercadorias. Com a ocupação francesa, foi se tornando cada vez mais um lugar de referência para refugiados artistas, intelectuais, anarquistas, comunistas, cristãos progressistas, judeus e outros alvos dos nazifascistas. Um lugar de passagem também para aqueles tidos como loucos. Para Tosquelles, essa era a importante característica de um hospital psiquiátrico: um lugar de passagem, segundo ele, de asilo somado a "uma característica geral da psicanálise: a necessidade de inventar"

Leitor do psiquiatra alemão Hermann Simon, a partir da sua proposta de Ergoterapia - que em oposição a clinoterapia (repouso no leito) desenvolveu uma psicoterapia ativa e pautada na atividade constante e devidamente orientada - o catalão aproveitou o contexto propício e incitou o interesse pelo trabalho. Como terapêutica contra o delírio, em muito impulsionado pelo ócio, procurou organizar a rotina por meio de atividades diversas das quais os pacientes participavam consensual e ativamente, fazendo-as, propondo-as, sem intervenções médicas, mas juntos. A figura do chefe de ala foi abolida. Todos eram consultados e todos podiam decidir. Essa experimentação foi nomeada de Clube Paul Balvet. O fazer artístico era impreterível, especialmente em grupos de teatro. Os surrealistas Paul Élluard e Georges Sadoul liam e organizavam publicações clandestinas com os textos dos pacientes (CONDE, 1998). Essa prática era uma das mais caras ao Clube e se desdobrou na publicação regular do jornal Trait D’Union.

Os pacientes, junto com outras pessoas que viviam em Saint-Alban, médicos ou não, saíam pelos campos em busca de alimentos. Isto fez do hospital um dos poucos lugares em que os internados sobreviveram à fome. Ainda segundo Heliana Conde, ao menos 40 mil pessoas internadas em instituições psiquiátricas francesas, frente à guerra e à ocupação do país, foram abandonadas e morreram de fome. Outras incontáveis foram transferidas para os campos de concentração. Segundo Tosquelles, a experiência em Saint-Alban buscava subverter: "os muros protegiam os doentes dos malefícios da família e dos malefícios da sociedade" e, mesmo que permanecessem os muros, as portas não tinham trancas e eram abertas frequentemente para quem quisesse sair e não mais voltar ${ }^{8}$.

Daí, surgiu a Psicoterapia Institucional, pela ação e implementação de artistas e militantes combativos em fuga, notadamente os que escaparam da Espanha franquista, junto com os "desarrazoados". Contudo, como mostrou Conde (1998), em artigo escrito quando a Reforma Psiquiátrica no Brasil estava na agenda do Estado, as práticas 
experimentadas em Saint-Alban já tinham perdido, em grande medida, seu caráter radicalmente contestador. E a medicalização, inicialmente por meio de tranquilizantes, já estava amplamente difundida.

Os franceses comunistas, pós II-Guerra Mundial, envolvidos nessas inventivas experiências, rapidamente passaram a servir ao assujeitamento soviético. Entretanto, o que aconteceu em Saint-Alban proliferou por outros espaços e repercutiu em importantes reflexões e obras do século passado. Por lá passaram Jean Dubuffet, Auguste Forestier, Tristan Tzara, Franz Fanon, Georges Canguilhem, que esteve no hospital enquanto escrevia O Normal e o Patológico (RUIZ, et al, 2013). Jean Oury passou dois anos em Saint-Alban e, muito próximo a Tosquelles, realizou trabalhos no Clube envolvendo o teatro e foi com o psiquiatra catalão a regiões distantes, atender casos mais complicados. Os dois romperam e Oury levou o que aprendera ali para outros hospitais. Em 1953, chegou ao Castelo de La Borde, em Cour-Cheverny, com poucos pacientes e pouco dinheiro. Em companhia de Félix Guattari, que conhecera poucos anos antes na clínica Saummery, difundiu a Psicoterapia Institucional, sobressaindo, em popularidade, a SaintAlban. Por La Borde passaram também Pierre Clastres e Fernand Deligny.

\section{ainda era de ferrolhos... ou bum!}

"era uma vez um burro, adulto há alguns anos e mestre-escola profissional, que batia constantemente nos jovens cordeiros porque suas orelhas não cresciam rápido o suficiente. ao seu lado, um velho gerânio ensinava às jovens violetas como elas deveriam enrubescer. seguindo o mesmo trabalho, um velho melro ensinava a duas jovens corujas os segredos para cantar bem. e esse centro de reeducação era célebre no mundo inteiro pela excelência de seu método, mas não pela eficácia de seus resultados" (fernand deligny).

As reformas na saúde pública (saúde mental) decorrentes da nova lei e resultantes do movimento antimanicomial redimensionaram o território de confinamento da loucura em novos territórios flexíveis, aproximaram as unidades estatais dos bairros dos necessitados de tais serviços e acabaram por substituir a relação com o paciente pela relação com o cliente e a sua liberdade de "escolha" do especialista: efeito de mercado, repercutindo a privatização da psiquiatria, o mote aos atendimentos psicológicos e às 
sessões psicanalíticas. Ou, ainda, este foi o possível para melhorar o atendimento e o tratamento com os pés-no-chão, porque a antipsiquiatria é uma utopia para se realizar no futuro quando a sociedade for igualitária. As alegações são semelhantes às que o sistema penal dá para as práticas abolicionistas penais.

A reforma psiquiátrica, não só no Brasil, foi um misto de abordagens oscilando entre juízos liberais e marxistas, incluindo as variadas tonalidades em cada um. A rubrica antimanicomial ajustou a todos entre as clientelas medicalizadas. A sociedade das disciplinas mostrou mais uma vez como cedeu e se ajustou à sociedade de controles a céu aberto. Porém, a medicalização que ocorria nos territórios de confinamentos ganhou ampliações na nova estratégia, dando à psiquiatria um novo fôlego para permanecer dominante (principalmente no governo da sanidade mental e moral de pobres e miseráveis). O que foi antipsiquiatria, antes de sua institucionalização, já estava redimensionada em luta antimanicomial por melhores condições de atendimento e direitos ao usuário e à sua família por tratamento. Nada mais de loucos e loucas ou doentes mentais; agora, só portadores de transtornos, todos os habitantes do bairro, da região, da cidade, do país, do planeta sob a gestão da OMS-ONU (Organização Mundial da SaúdeNações Unidas) de todos os clientes em novos espaços descentralizados de atendimento. Com maiores ou menores gravidades, cada um deve ser atendido em espaço aberto. A relação bairro-comunidade recheada de pessoas convivendo com o louco-doente mental permaneceu obstruída em função do atendimento aos portadores de direitos inacabados em meio aberto. O pensamento libertário, que tocou o movimento antipsiquiátrico (CONDE, 2020), esvaeceu (ALONSO, 2014).

É preciso radicalizar, como fizeram xs anarquistas na Espanha e os diversos subversivos na França. Ultrapassar as fronteiras e demolir não apenas os muros. Michel Foucault mencionou as práticas antipsiquiátricas experimentadas na Revolução Espanhola e desdobradas desde Saint-Alban e enfatizou que foram limitadas, perguntando e respondendo:

por que essas iniciativas não foram muito longe? Porque os psiquiatras franceses são, direta ou indiretamente, ligados à administração, aos responsáveis administrativos e jurídicos do hospital. Exercendo esse poder, eles não estão em condições de criticar o poder administrativo em nome do poder médico, nem o poder médico em nome de um pensamento que seria ao mesmo tempo livre da medicina e da administração. Eles puderam opor-se à medicina e à administração, sem poder liberar-se nem de uma nem da outra (FOUCAULT, 2011c: 351). 
Em sua passagem pelo Brasil, Foucault escreveu o breve texto "O mundo é um grande hospício", publicado na revista Manchete, em 1973, onde afirma: “a importância da antipsiquiatria está no fato de ela pôr em dúvida toda uma certeza do médico, o poder que ele tem de decidir sobre o estado mental de um indivíduo" (FOUCAULT, 2011a: $308)$.

Lima Barreto, escritor anarquista, preto e bêbado, esteve trancado no Hospício Nacional, no Rio de Janeiro, duas vezes, em 1914 e, novamente, em 1919. Ao lado de outros pretos e bêbados, de mulheres, crianças, leprosos, tuberculosos, epilépticos, loucos, ladrões, vagabundos, miseráveis, potencialmente perigosos, uma "corte de indesejados", o libertário enfrentou os médicos e psiquiatras. Explicitou como eles eram mais comprometidos com valores morais do que com a alegada cura; como exerciam seu poder por meio de castigos, humilhações, violências. A fé na ciência, supostamente inquestionável, foi propositalmente estancada pelo escritor (ARANTES, 2008). Os escritos de Lima Barreto, além da contundência analítica, são um raro registro de histórias que tendem a ser esmagadas, desaparecidas como se tentou - e, por vezes, ainda se tenta - fazer com as existências trancadas dentro dessas instituições, ou, hoje em dia, ao enaltecer alguns resultados artísticos obtidos em terapias com os clientes, quando no passado eram simplesmente atiradas aos escaninhos mofados dos funcionários ubuescos. Mais de um século se passou e muito permanece intocado ou ajustado às revisões e aos controles a céu aberto no presente. E comunidade terapêutica virou negócio de evangélicos para curar drogaditos e gays segundo uma moral reacionária da normalização caquética; e hospício continuou sendo a casa de loucos.

De acordo com o Censo Psicossocial (2014), o alvo majoritário nos hospitais psiquiátricos e que ficam esquecidos por lá são homens $(62,1 \%)$, autodeclarados brancos $(65 \%)^{9}$, solteiros $(86,9 \%)$, que têm entre 50 e 59 anos, baixa escolarização (não alfabetizados ou que somente escrevem o próprio nome), nunca trabalharam (41,6\%) e possuem apenas um diagnóstico $(82,7 \%)$. Ao passo que a maioria não tem doenças clínicas e só um diagnóstico de transtorno mental, quase todos $(93,2 \%)$ tomam múltiplos remédios ${ }^{10}$.

Encomendado por órgãos do governo de estado de São Paulo, intitulado "Caminhos para a Desinstitucionalização", o relatório buscou traçar o perfil da população internada por longo período, esquecida em 53 hospitais psiquiátricos. Apesar de desatualizado, o levantamento pode dar pistas dos que continuam presos nessas instituições em todo o país, uma vez que o estado de São Paulo é o que mais confina e 
que mais possui hospitais psiquiátricos, sediando o maior da América Latina, o Instituto Américo Bairral de Psiquiatria, localizado em Itapira.

Na época eram 4.439 pessoas trancadas, pelo menos há cinco anos, e consideradas “em condições de ressocialização". No primeiro censo em 2008, foram localizados 6.349 pacientes nessas condições. A diferença de 1.910 pessoas se deu, em grande medida, pela morte de 1.170. Mais óbitos do que altas médicas e fugas. A maioria dos internados (74,5\%) está há mais de 10 anos no hospital, sendo o intervalo mais frequente de 16 a 20 anos de internação. Foi o equivalente a um terço ou metade de suas vidas trancafiados ali. São muito poucos os que saem e os que recebem visitas. As visitas e saídas diminuem, rareiam, conforme o tempo de internação se arrasta.

O maior número de "encaminhamentos" provém de transferências entre hospitais psiquiátricos e casas de repouso. Mas $5,1 \%$ o foram por ordem judicial ${ }^{11}$, sob a justificativa de serem potencialmente perigosos, pois não haviam cometido "delito ou crime". 3,2\% foram presos quando crianças ou jovens por determinação da justiça, encaminhados pela Fundação Casa/Febem, abrigos de menores ou conselho tutelar. O percentual das internações de crianças e jovens diminuiu. Mas ainda são aprisionados também nas instituições psiquiátricas.

O mais recente documento publicado sobre os hospitais psiquiátricos expõe os resultados de uma inspeção nacional em 40 hospitais de grande porte espalhados pelas cinco regiões do país, realizada em dezembro de 2018 (CONSELHO FEDERAL DE PSICOLOGIA et al, 2019). Em setembro daquele ano havia 131 hospitais psiquiátricos no Brasil. O longo relatório elenca e descreve um tanto de violências perpetradas nestas instituições e os lugares insalubres, abarrotados, com o lixo entulhado, os cheiros intragáveis. Como sempre: as camas e colchões carcomidos, os banheiros sem portas, sem água e papel higiênico. A comida mal serve para matar a fome; há o impedimento de beber água quando com sede e do banho quando quiser. O isolamento prepondera sem acesso às notícias, não poder fazer uma ligação ou escrever para fora sem a mediação e a censura de funcionários. O ócio e o tédio são insuportáveis. As visitas quase nunca chegam. O trabalho forçado pela barganha de um cigarro ou um suposto pequeno privilégio. As constantes drogas médicas que, dose a dose, reduzem a vitalidade. A proibição à saída: para uma volta mais tarde ou para conter a decisão de ir embora. Inexiste internação voluntária, pois não se pode sair sem a alta. E há inúmeros casos sem diagnóstico, sobre quem não se sabe o porquê ou como foi parar ali. Mas foi. Alguém almejou sumir com essa pessoa e ela sumiu ali. 
Inexiste internação voluntária, também porque quem tenta fugir e é pego é imediatamente castigado. Amarram com as contenções mecânicas, dopam com as circunscrições químicas: coquetéis de medicamentos que incluem haldol, neozine, diazepam, quetiapina, carbozepina, amplictil e outras. Isolam em quartos similares às celas solitárias; batem, ameaçam, espancam, torturam; quem questiona, desobedece, briga, tenta fugir, se masturba, "causa problemas", "não para quieto", "agita"; tem “exacerbação sexual" e "de libido", comportamentos "inadequados"...

As amarras são utilizadas também em idosos, pessoas com dificuldade de mobilidade ou "quadro neurológico"; quem apresenta "risco de suicídio" e autolesivos. A meta é inibir tentativas suicidas e também a mais recorrente justificativa para aplicação de castigos mais longos e contínuos.

Há mulheres grávidas internadas. Quando nascerem, os bebês serão sequestrados pelo Estado ou pela família responsável. Há jovens, menores de 18 anos, internados. São internações chamadas involuntárias a pedido dos pais e responsáveis, com a orientação dos médicos. A maioria são garotos, presos pelo uso de álcool e outras drogas classificadas como ilícitas. São as chamadas internações compulsórias, a mando do juiz, do conselho tutelar, da autoridade do pequeno município que almeja desaparecer com esses jovens e os enfiam em hospitais psiquiátricos a quilômetros de distância. Mesmo com alta médica, são largados lá, sem a revisão judicial que funciona com "prazo dilatado". Menos do que medidas de suposto tratamento de saúde, os jovens são internados por medidas de segurança, por serem um perigo, "um risco social".

As crianças, em geral, ficam confinadas nas alas neurológicas. Os idosos também, muitas vezes amarrados ou dopados no leito. São "pessoas com deficiências, transtorno neurológico e/ou quadro psiquiátrico agudo", internadas em longa duração por decisão da família ou por não possuírem família ou quem esteja com elas. A sociedade das disciplinas, dos confinamentos, dos hospícios permanece como a vida da gosma.

Tanto o relatório de inspeção dos hospitais quanto o Censo concluem reiterando a importância das Redes de Atenção Psicossocial (RAPS), dos CAPS, dos Serviços Residenciais Terapêuticos, do Programa de Volta para Casa (PVC), do Sistema Único da Assistência Social (SUAS) e da Rede de Cuidados à Pessoa com Deficiência, como estratégias para a desinstitucionalização; recomendam a inibição de internações longas e a redução da morosidade na liberação daqueles classificados como "em condições de ressocialização"; defendem a necessidade de maior compromisso com os direitos da criança e do adolescente e os direitos humanos, como forma de impedir as torturas e os 
“excessos" de "contenção"; além do papel da família, que só pode ser entendida enquanto mais uma instituição comparsa, pois grande parte das pessoas internadas nos hospitais psiquiátricos o foi a pedido ou com anuência dos familiares.

Em 2018, constatou-se o aumento nos gastos estatais com as internações, os hospitais e a política de drogas. Um ano antes, fora realizada uma inspeção semelhante em 28 das mais de 2 mil Comunidades Terapêuticas (CTs). O resultado foi similar ao da verificação nos hospitais psiquiátricos. Castigos e violências. Execução de tarefas forçadas e repetitivas. Imposição de cópias de trechos bíblicos. Aumento da laborterapia. Trabalho forçado, sem qualquer remuneração, voltado para a manutenção do espaço físico e das tarefas cotidianas, como as de limpeza. Interdição de acesso a uma ou mais refeições. Fome. Privação do sono. Isolamento. Socos nos olhos, medicação empurrada goela a baixo, corpos atados; castigos aplicados especialmente em tentativas de fuga ${ }^{12}$.

As amarras e os coquetéis de drogas farmacêuticas (conhecidos nesses lugares como danoninho e garapa), chamados de contenções, são aplicados também às condutas consideradas violentas, aos "surtos" e às "crises de abstinência". As condutas sexuais consideradas inadequadas, pelo caráter religioso destas instituições, são punidas com “despossessão", "cura" ou "reversão" sexual.

Como nos hospitais, não podem sair, ter contato com o exterior, ligar ou escrever livremente para familiares e amigos. As comunicações, quando ocorrem, também são mediadas e censuradas. Bens e documentos permanecem sob a guarda da instituição e de seus funcionários. Como os hospitais, a maioria das CTs fica em lugares de difícil acesso. Como nos hospitais psiquiátricos e nas prisões, nelas fazem revistas vexatórias e íntimas em visitantes. Como nos hospitais e nas prisões, os muros são muito altos, com arames farpados, concertinas, guaritas e câmeras.

Nas Comunidades Terapêuticas há crianças e jovens internados. Crianças "acompanhando" as mães. Crianças e jovens confinados por ordem judicial, a mando do pastor ou a pedido da família. Há jovens presos como medida socioeducativa, por furto, uso de armas ou por não frequentarem a escola. Há casos em que os jovens sequer fazem uso de álcool e outras drogas, mas são internados, simplesmente, para sumir com eles. Dependem da decisão do juiz que, como nos hospitais psiquiátricos, é o principal sentenciador do aprisionamento de jovens.

Há pacientes com diversos transtornos mentais diagnosticados e que não bebem ou usam drogas ilícitas. São depressivos, bulímicos, autistas. Há idosos que, muitas vezes, são internados por não terem lugar para habitar ou alguém que se interesse por eles; se 
precisam de apoio diário, encontram-no nessas instituições junto a outros pacientes. Há gente que vivia nas ruas e foi para a CT, geralmente encaminhados após "trabalho voluntário" de fiéis da igreja vinculada ao empreendimento. "Além disso, algumas das comunidades terapêuticas visitadas têm sido utilizadas para internação de pessoas com comportamentos considerados moralmente desviantes da norma, daí o registro de internações por 'agressividade e rebeldia' ou 'deficiência intelectual" (CONSELHO FEDERAL DE PSICOLOGIA et al, 2018: 136).

Hoje, no Cadastro Nacional de Estabelecimentos de Saúde, contabiliza-se 2.990 leitos para saúde mental em hospital-dia (sendo 1.089 do SUS); 3.201 leitos clínicos (sendo 1.817 do SUS); 295 leitos para atendimentos de internação nos Centros de Atenção Psicossocial; 3.137 leitos em atendimento ambulatorial e 98 de urgência.

Enquanto o número de leitos em hospitais psiquiátricos teve forte queda nos últimos anos, as comunidades terapêuticas cresceram em quantidade e buscam se consolidar como opção de tratamento imediatamente disponível. (...) As CTs foram inseridas nas políticas públicas nacionais de atendimento aos usuários de drogas, inclusive com a transferência de recursos federais. Paulatinamente, as politicas de saúde mental também abriram possibilidades para que passassem a integrar os componentes da rede de atenção psicossocial, em um processo controverso e permeado por resistências e disputas (CONSELHO FEDERAL DE PSICOLOGIA et al, 2018: 22).

Em dezembro de 2011, o Ministério da Saúde formalizou a Rede de Atenção Psicossocial (RAPS), voltada para pessoas com "sofrimento ou transtorno mental e com necessidades decorrentes do uso de crack, álcool e outras drogas" no âmbito do SUS, e instituiu as CTs como prestadoras de serviços de saúde destinados a estas pessoas (Portaria MS/GM no 3.088/2011). Pouco tempo depois, as comunidades passaram a receber incentivos financeiros estatais e, posteriormente, foram reconhecidas pelo Conselho Nacional de Políticas sobre Drogas (Conad) ${ }^{13}$.

O Conselho Federal de Medicina também atualizou suas normas frente à ampliação e reconhecimento das comunidades terapêuticas, por meio da definição dos serviços, ambientes médicos e condições mínimas para internação (Resolução no 2.056/2013). Distingue, assim, as CTs médicas e as não médicas. Notam-se aí as disputas e negócios profícuos entre forças médicas, religiosas e estatais atravessadas pela lucrativa política nacional de drogas e pela indústria farmacêutica. A questão moral em relação ao uso de substâncias alteradoras de consciência, intocada pela luta antimanicomial, pode ter sido a porta de entrada para a retomada e o recrudescimento da internação em instituições asilares, que segue em curso, quase sem alarde. 
Por meio do investimento na RAPS, depois das CTs, incluíram-se os "hospitais psiquiátricos especializados", ao mesmo tempo que se reiterava a continuidade da redução de internações e a proibição da ampliação do número destes leitos hospitalares (Portaria GM/MS n. 3.588, de 21 de dezembro de 2017). Mais recentemente, o governo federal instituiu uma Rede mais plural: "não considera mais Serviços como sendo substitutos de outros, não fomentando mais fechamento de unidades de qualquer natureza. A Rede deve ser harmônica e complementar. Assim, não há mais porque se falar em 'rede substitutiva', já que nenhum Serviço substitui outro" (MINISTÉRIO DA SAÚDE, 2019: 3-4). Mais adiante, explicita-se: "Não cabe mais a ideia de que Hospitais Psiquiátricos devem abrigar moradores. Porém, também não cabe mais a ideia de que tais Serviços devam ser fechados" (MINISTÉRIO DA SAÚDE, 2019: 8).

Nesta cilada, anunciou-se o aumento de verbas para a implementação de medidas de prevenção (possivelmente mais internações) nos estados com maiores números de suicídio, e para eletroconvulsoterapia. O Estado passa a financiar a atualização dos eletrochoques, já aplicados nos hospitais psiquiátricos, inclusive em jovens (CONSELHO FEDERAL DE PSICOLOGIA, 2019), cuja internação se torna ainda mais incentivada:

(..) deve-se colocar como exemplo o caso de internação de crianças e adolescentes em unidades psiquiátricas. Vale ressaltar que não há qualquer impedimento legal para a internação de pacientes menores de idade em Enfermarias Psiquiátricas de Hospitais Gerais ou de Hospitais Psiquiátricos. A melhor prática indica a necessidade de que tais internações ocorram em Enfermarias Especializadas em Infância e Adolescência. No entanto, exceções à regra podem ocorrer, sempre em benefício dos pacientes (MINISTÉRIO DA SAÚDE, 2019: 24).

No Brasil, aprisionam-se crianças e jovens em unidades de internação socioeducaticas, comunidades terapêuticas e hospitais psiquiátricos.

$\mathrm{Na}$ tese Loucura e direito penal: pistas para a extinção dos manicômios judiciários, Haroldo Caetano (2018) mostra as interfaces entre as medidas de segurança e a saúde mental no Brasil. O Programa de Atenção Integral ao Louco Infrator (PAILI), implementado no estado de Goiás, desde 2006, é apresentado como "a plena viabilidade de uma vida sem manicômios judiciários" (CAETANO, 2018: 16), uma ruptura com a lógica manicomial instituída pelo Estado, como programa de governo. Tudo o que ele verificou e relatou sobre o funcionamento dos manicômios judiciários ocorre de maneira espelhada nos hospitais psiquiátricos e nas comunidades terapêuticas. Caetano identificou também uma mudança em curso quanto ao perfil dos “eleitos para os manicômios, os 
novos perigosos (...), indivíduos que fazem uso problemático de substâncias psicoativas" (CAETANO, 2018: 105, grifos do autor).

Perseguindo brechas legais para políticas antimanicomiais, nota-se como estas operam concomitantemente aos hospitais psiquiátricos e aos manicômios judiciários, incluindo as CTs. O modelo transitório, até mesmo o modelo do programa goiano, não rompe com este circuito, opera para dinamizar, escalonar ou reduzir a seletividade. $\mathrm{O}$ funcionamento da articulação entre segurança e saúde mental não se restringe aos manicômios judiciários. Romper com ele, com as internações, os aprisionamentos e castigos, não é possível por meio da lei. Como não é possível por meio da aplicação de modelo lidar com cada loucura e a loucura de cada um.

Os acontecimentos revolucionários foram importantes para implodir encarceramentos, como sua continuidade em torno da reforma da soberania gerou permanência dos confinamentos conectados com o monitoramento no controle a céu aberto. Não é estarrecedor constatar a mutação do campo de concentração em campo de concentração a céu aberto, tampouco a emergência do intelectual modulador, capaz de acionar ativismos e moderações ajustadas a medidas que repercutam democracia nas relações fundadas em direitos de minorias e em seus portadores (PASSETTI et al., 2019).

A luta anti é pela abolição de práticas e instituições: o que é ou foi no passado a antipsiquiatria jamais se assemelha ou assemelhará às práticas antimanicomiais. Estas compõem modulações com as disciplinares, os aprisionamentos, as medicalizações confinadas ou a céu aberto. A realidade, mais que a lei e os programas alternativos mostra como situou o poeta René Char: "aquilo que veio ao mundo para nada perturbar, não merece respeito nem paciência”.

\section{referências}

Conselho Federal de Psicologia, Mecanismo Nacional de Prevenção e Combate à Tortura, Conselho Nacional do Ministério Público, Ministério Público do Trabalho. "Hospitais psiquiátricos no Brasil: relatório de inspeção nacional”, 2019. Disponível em:

\section{https://site.cfp.org.br/wp-content/uploads/2019/12/Relatorio_Inspeca_HospPsiq.pdf}

Conselho Federal De Psicologia, Mecanismo Nacional De Prevenção E Combate À Tortura Procuradoria Federal Dos Direitos Do Cidadão/Ministério Público 
Federal. "Relatório da inspeção nacional em comunidades terapêuticas - 2017", 2018. Disponível em:

https://site.cfp.org.br/wp-content/uploads/2018/06/Relatorio-da-inspecao-nacional-emcomunidades-terapeuticas_web.pdf

Dorothea Voegeli Passetti. A atualidade de Dubuffet: cultura asfixiante. Revista Verve, 16. São Paulo: Nu-Sol, 2009, pp. 150-165. Disponível em: http://www.nusol.org/wp-content/uploads/2018/02/verve16.pdf

Edson Passetti. Heterotopias libertárias. Revista Verve 2. São Paulo: Nu-Sol, 2002, pp. 141-173. Disponível em: http://www.nu-sol.org/wpcontent/uploads/2017/11/verve2.pdf

et al. Ecopolítica. São Paulo: Hedra, 2019.

Felipe Magaldi. Mania de liberdade. Nise da Silveira e a humanização da saúde mental no Brasil. Rio de Janeiro: Editora Fiocruz, 2020.

Fernand Deligny. Semente de crápula. Conselho aos educadores que gostam de cultivála. Tradução de Juliana Jardim e Luiz Pimentel. São Paulo: n-1 edições/hedra, 2020.

Francisco Javier Montejo Alonso. En un lugar de La Mancha... Francesc Tosquelles y Max Hodann, creadores de las primeras comunidades terapéuticas durante la Guerra Civil Española. Intersubjetivo: Revista de Psicoterapia Psicoanalítica y Salud, Vol. 14, №. 1, Madrid: Quipú, 2014, pp. 47-67. Disponível em: https://dialnet.unirioja.es/revista/17550/V/14

Fundap; Governo do Estado de São Paulo. Caminhos para a Desinstitucionalização no Estado de São Paulo: Censo Psicossocial 2014, 2014. Disponível em: https://www.saude.sp.gov.br/resources/ses/perfil/profissional-da-saude/grupotecnico-de-acoes-estrategicas-gtae/saude-mental/censopsicossocial/censo_psicossocial_2014.pdf

Georges Canguilhem. O cérebro e o pensamento. Natureza Humana 8(1), on line. Tradução de Sandra Yedid e Monah Winograd. São Paulo, jan.-jun. 2006, pp. 183210. Disponível em:

http://pepsic.bvsalud.org/scielo.php?script=sci_arttext\&pid=S1517$\underline{24302006000100006 \& \operatorname{lng}=\mathrm{pt} \& \mathrm{nrm}=\mathrm{iso}}$

Gustave Courbet. Carta aos amigos de Paris. Revista Verve. 13, São Paulo: Nu-Sol, 2009, pp. 123-125. Disponível em: http://www.nu-sol.org/wpcontent/uploads/2018/02/verve15.pdf

Gustavo Simões. A origem de um mundo, dois amigos libertários. Revista Verve 24, São Paulo: Nu-Sol, 2013, pp. 204-210. Disponível em: http://www.nu-sol.org/wpcontent/uploads/2018/01/verve24.pdf

Haroldo Caetano. Loucura e direito penal: pistas para a extinção dos manicômios judiciários. Tese de doutorado. Niterói: Universidade Federal Fluminense, 2018.

Heliana Conde. Ensaios sobre Michel Foucault no Brasil. Rio de Janeiro: Lamparina, 2016.

. "Um anarquista catalão: aventuras do freudo-marxismo na França". Cadernos de Psicologia, Rio de Janeiro, v. 8, p. 151-170, 1998. Disponível em: 
https://www.academia.edu/29032705/Um_Anarquista_Catalão_aventuras_do_fr eudo_marxismo_na_França

As subjetividades em revolta. Rio de Janeiro: Lamparina/Faperj, 2020, pp. 157-164.

Jean-François Gomez. “Traces vivantes de Tosquelles et de quelques autres”, 2010.

Disponível em: https://www.cairn.info/revue-vie-sociale-et-traitements-2010-1page-123.htm

Josep M. Comelles. Forgotten paths: Culture and ethnicity in Catalan mental health policies (1900-39). History of Psychiatry, 2010, pp. 406-23. Disponível em:

https://www.researchgate.net/publication/51605325_Forgotten_paths_Culture_and_ethn icity_in_Catalan_mental_health_policies_1900-39

Marco Antonio Arantes. Hospício de Doutores. Hist. cienc. saude-Manguinhos, vol.15 no.1, Rio de Janeiro, 2008. Disponível em:

https://www.scielo.br/scielo.php?script=sci_arttext\&pid=S0104-59702008000100004

Max Stirner. O único e a sua propriedade. Tradução de João Barrento. São Paulo: Martins Fontes, 2009.

Arte e religião. Revista Verve. 4, São Paulo: Nu-Sol, 2003, pp. 67-78. Disponível em: http://www.nu-sol.org/wp-content/uploads/2017/11/verve4.pdf

Michel Foucault. Os anormais. Curso no Collège de France (1974-1975). Tradução de Eduardo Brandão. São Paulo: Martins Fontes, 2001.

A verdade e as formas jurídicas. Tradução de Roberto C. M. Machado e Eduardo J. Morais. Rio de Janeiro: Nau, 2005.

A coragem da verdade. Tradução de Eduardo Brandão. São Paulo: Martins Fontes, 2011.

"O mundo é um grande hospício". In: Manoel B. da Motta (org) Ditos e escritos VII. Tradução de Vera Lucia Avellar Ribeiro. Rio de Janeiro: Forense Universitária, 2011a, pp. 307-309.

"Hospícios, sexualidade, prisões". In: Manoel B. da Motta (org) Ditos e escritos VII. Tradução de Vera Lucia Avellar Ribeiro. Rio de Janeiro: Forense Universitária., 2011b, pp. 310-322.

"Michel Foucault, as respostas do filósofo". In : Manoel B. da Motta (org) Ditos e escritos VII. Tradução de Vera Lucia Avellar Ribeiro. Rio de Janeiro: Forense Universitária, 2011c, pp. 343-356.

"Confinamento, psiquiatria, prisão". In: Manoel B. da Motta (org) Ditos e escritos VI. Tradução de Ana Lúcia Paranhos Pessoa. Rio de Janeiro: Forense Universitária, 2011d, pp. 126-154.

Ministério da Saúde, Secretaria de Atenção à Saúde, Departamento de Ações Programáticas Estratégicas Coordenação-Geral de Saúde Mental, Álcool e Outras Drogas. "NOTA TÉCNICA No 11/2019-CGMAD/DAPES/SAS/MS. Esclarecimentos sobre as mudanças na Política Nacional de Saúde Mental e nas Diretrizes da Política Nacional sobre Drogas", 2019. Disponível em: https://drive.google.com/file/d/13by1kfwEhYmJn8cOhse86bG_RtEDb-v8/view

Pierre Clastres. A sociedade contra o Estado. Tradução de Theo Santiago. São Paulo: Francisco Alves, 1974. 
Rafael Llavona y Javier Bandrés. Psicología y anarquismo en la guerra civil española: la obra de félix martí-ibáñez. Psicothema, 1998. vol. 10, no 3, pp. 669-678, 1998. Disponível em: http://www.psicothema.com/pdf/195.pdf

Richard Cleminson. Anarquismo y Sexualidad (España, 1900-1939). Cádiz: Universidad de Cádiz Servicio de Publicaciones, 2008.

Valéria Salek Ruiz; Vladimir Athayde; Irapoan Nogueira Filho; Paulo César Zambronide-Souza; Milton Athayde. François Tosquelles, sua história no campo da Reforma Psiquiátrica / Desinstitucionalização e suas pistas para uma abordagem clínica do trabalho centrada na atividade, 2013. Disponível em:

https://www.e-publicacoes.uerj.br/index.php/revispsi/article/view/8596/6488

edson passetti é professor livre-docente na faculdade de ciências sociais e no programa de estudos pós-graduados em ciências sociais da puc-sp; coordena o núcleo de sociabilidade libertária (nu-sol) - www.nu-sol.org.

E-mail: edson.passetti@uol.com.br

flávia lucchesi é doutoranda em ciências sociais pela puc-sp e pesquisadora no nu-sol.

E-mail:: flalucchesi@gmail.com

1 Leon Hirzman. Imagens do inconsciente. Parte 1. Disponível em: https://www.youtube.com/watch?v=TJWVApX dBk; $\quad$ Parte $2 . \quad$ Disponível em: https://www.youtube.com/watch?v=p3O3HhHlT7g

2 Edson Passetti. Nise, 1998. Disponível em: www.nu-sol.org

${ }^{3}$ Sobre demais entrevistas do filósofo no Brasil, pertinentes ao tema, ver FOUCAULT, 2011b, 2011c.

4 David Cooper: “O movimento nos anos 1930 que ia em direção a uma ‘despsiquiatrização' na União Soviética, foi derrubado no curso do reino de Stalin.” (FOUCAULT, 2011d, p. 129). Ver também, https://elpais.com/diario/1976/12/29/internacional/220662008_850215.html (Acesso em 30/04/2021)

${ }^{5}$ http://www.planalto.gov.br/ccivil_03/Leis/LEIS_2001/L10216.htm

A registrar que em 2001 começa o Fórum Social Mundial, em Porto Alegre-Brasil, que produzirá a substituição da luta antiglobalização para altermundialismo.

${ }^{6}$ Daniele Sivadon e Jean-Claude Pollack. François Tosquelles: uma política da loucura, documentário, 1989. Disponível em: https://www.youtube.com/watch?v=kT9REbBckRI

7 TOSQUELLES apud SIVADON \& POLLACK, 1989.

8 TOSQUELLES apud SIVADON \& POLLACK, 1989.

${ }^{9}$ Quanto à etnia e raça há divergência com o relatado pelo Conselho Federal de Psicologia (2018), onde se destaca, pelas equipes que vistoriaram os hospitais psiquiátricos em todas as regiões do país, maior presença de homens negros.

${ }^{10}$ Os diagnósticos mais frequentes são de esquizofrenia (43,1\%), retardo mental (28\%), transtornos mentais orgânicos (18\%), transtornos mentais e comportamentais devidos ao uso de substância psicoativa (3,9\%), transtornos da personalidade e do comportamento do adulto $(2,1 \%)$. A maioria $(53,3 \%)$ não possui diagnósticos de doenças clínicas, só um diagnóstico de transtorno. Só 1,3\% não toma nem um remédio, sem qualquer diagnóstico psiquiátrico são $4,2 \%$.

11 As internações classificadas como compulsórias são justificadas por: agressividade, violência ou periculosidade; perda, abandono ou ausência familiar; menores de idade em instituição; transtorno ou estado mental alterado; medida de (res)socialização de segurança, processo criminal, dependência de substância química; casa de custódia, solicitação familiar; transferência institucional; falta de adesão ao 
tratamento; ter sofrido maus-tratos físicos ou abuso sexual. Ou ainda, "outros motivos" e "não consta" $(15,8 \%)$.

12 Em muitas CTs, as violências começam com os "resgates" ou "remoções", contratados como serviço extra pelas famílias, e realizados por seguranças das Comunidades ou de empresas terceirizadas.

${ }^{13}$ Em 2012, foi criada a Confederação Nacional de Comunidades Terapêuticas (Confecnat) - pela aliança entre Federação Norte e Nordeste de Comunidades Terapêuticas (Fennoct), Cruz Azul No Brasil, Federação Brasileira de Comunidades Terapêuticas (Febract), Federação das Comunidades Terapêuticas Evangélicas do Brasil (Feteb) e Obra Social Nossa Senhora Da Gloria Fazenda Esperança (Fazendas Esperança) marcando o investimento das igrejas neopentecostais e, já naquele momento, a ampla participação e negociação com o governo federal. A entrada no Conad remete à Res. PR/GSI/CONAD n 1/2015. 